Educational Research for Social Change (ERSC)

Volume 7 No. 2, September 2018

pp. 132-145

ersc.nmmu.ac.za

ISSN: 2221-4070

\title{
Green sprouts: Transformative learning in learning through participation (LTP)
}

Phyllis Sakinofsky (affiliation)

Macquarie University

phyllsak@gmail.com

María Florencia Amigó

Macquarie University

Maria.amigo@mq.edu.au

Avril Janks

Macquarie University (affiliation)

avriljanks@hotmail.com

\section{Abstract}

This article explores the transformative learning effects of university courses that integrate academic learning with practical experience, highlighting in particular the tripartite learning that may occur where students are encouraged to work collaboratively with external partners as well as with their university teachers. We make the proposition that the student can act as the catalyst for this emancipatory perspective, and that critical reflection is necessary to achieve this outcome. Finally, we propose a four-step model that can be used by students, their teachers, and placement supervisors to scaffold the critical reflection process during an experiential learning placement.

Keywords: transformative learning, learning through participation, critical reflection, sustainable learning, reflective metacognitive learning, work integrated learning

Copyright: (C) 2018 Phyllis Sakinofsky, María Florencia Amigó \& Avril Janks

This is an open access article distributed under the terms of the Creative Commons Attribution Non-Commercial License, which permits unrestricted non-commercial use, distribution, and reproduction in any medium, provided the original author and source are credited.

Please reference as: Sakinofsky, P., Amigo, M. \& Janks, A. (2018). Green Sprouts: Transformative Learning in Learning Through Participation (LTP). Educational Research for Social Change, 7(2), 132145. http://dx.doi.org/10.17159/2221-4070/2018/v7i2a9

\section{Introduction}

Through academically supported placements, students can apply knowledge acquired in university courses to actual situations, projects, or cases that are accessed through university partner organisations. In these situations, students are encouraged to put theory into practice and to develop professional skills and attitudes. We argue, in this article, that placements that are academically supported may lead to transformative and sustainable learning experiences for all involved, not just 
the student, and contribute meaningfully to civil society-and are particularly pertinent to placements with organisations working for social change.

Enhancing the relationships between universities, industry, and community organisations is a growing priority for the tertiary sector around the world. In Australia, where the authors are based, a recent discussion paper by Australian Collaborative Education Network (ACEN) and other bodies representing the university sector, encouraged enterprises, educators, and the community to work together to improve the quality and capacity of education systems. The paper advised, "These linkages are crucial if we are to succeed in meeting the challenges and opportunities presented by rapidly changing global realities" (ACEN, 2015, p. 1).

This collaboration between universities and external organisations is also endorsed by the movement towards education for sustainability, a school that proposes building capacity for futures-oriented thinking, and learning decision making that considers the future of the economy, ecology, and the advancement of equitable societies. According to Gewessler and Norris (2013), transformative learning is a fundamental requirement if sustainability is to be embedded into teaching, learning, and curriculum.

In this article, we propose that university student placements have great potential to lead to sustainable transformative learning. Motion and Burgess (2014) noted that solidly supported and planned student placements-including the critical reflection by the student that may accompany a university placement-can foster students' understanding of how knowledge systems and ideological and power structures operate in the workplace and, therefore, may encourage students in developing a commitment to values such as civic responsibility, social inclusion, and equity. We will argue that these transformative processes anchored in a student's placement can be expanded to include the university and the partner, when working together as a triad. Drawing from the connection established in the literature between academically supported placements, critical reflection, and transformative learning, we will argue that if university teachers and university partners are supported as learners and contributors in this process, in the same way students are, the results can be more powerful and transformative.

Based on our review of the literature on learning through participation (LTP) ${ }^{1}$ and its connection to reflection and transformative learning, we suggest that it is not mere reflection that leads to significant learning but also an engaged, conscientious, thorough, and critical reflective process that challenges previous assumptions and frames of reference and leads to a meaningful and transformative learning outcome. We take this even further positing that, with the student being the catalyst for change, the external partner and the university teacher may also experience transformative learning because they are working with students and are learning through students' learning. Further, with appropriate scaffolding, this process could be the precursor for meaningful and collaborative social change. We have found no literature on this proposition, nor models to guide the triad through the reflection process that may lead to transformative learning.

Many scholars have written that students are often exposed to meaningful and multifaceted learning opportunities when placed in organisations (for example, Fitch, 2011; Gewessler \& Norris, 2013; Mackaway, Winchester-Seeto, Coulson, \& Harvey, 2011; Trede, 2012; Valle, 2006). Metacognitive learning (Williams, 2004) or transformational reflection (Rarieya, 2005) are concepts that have been

\footnotetext{
${ }^{1}$ This term was introduced by Mackaway et al. (2011) as an umbrella concept that refers to experiential learning of students through their engagement in the public, private, or not-for-profit sectors that is supported by the university curriculum and involves assessment of student learning.
} 
used to account for the potential impact of experiential learning. However, there is a need to identify the mechanisms that allow for these to happen-and not only for the student but also for all those involved in the process. Outlined later in this article, our SPROUT model, centred on self- and critical reflection, aims to fulfil that purpose.

Dewey (1910/1933) recognised the moral basis of reflection and experimentation of action so, although reflective practice in education has been promoted as crucial for teachers and students for several decades, there is still debate around the term reflection being too vaguely defined. In addition, how it distinguishes itself from other forms of thinking is not always made explicit (e.g., Rodgers, 2002). For Dewey, reflection needs to be a systematic process that engages both the intellect and the emotional; its intention is to derive meaning from experience, establish the continuities between experiences and, ultimately, bring an individual from a state of disequilibrium or confusion to one of clarity. Rodgers (2002) emphasised that the experimentation or theory testing component of Dewey's proposition-usually overlooked in understandings of reflection in education-is crucial for the reflective cycle to prosper and build upon previous instances of disequilibrium-equilibrium. For Leitch and Day (2000) this equated to action research, which they considered central to educators' responsibility to be inquirers who engage in collaborative research that generates knowledge out of their practice.

The sociological literature has also closely engaged with the concepts of reflection and reflexivity as conditions that counteract habitual action. Archer (2012) has written extensively on this thesis, arguing that, especially in our modern times, socialisation as a way of acquiring inherited habits "has been decreasingly able to prepare for occupational and lifestyle opportunities that had not existed for the parental generation," meaning that our increasing need to "relocate, retrain, and reevaluate" requires a degree of reflexivity that will incite social agents to action and change (p. 298). Archer's thesis underpins our proposition in this article.

\section{Method}

A literature review was undertaken to examine the potential for student placements framed within their university curriculum to offer transformative learning experiences. Relevant sources were identified using Academic Search Premier and Sage Journals Online databases, and guided through these key terms: work integrated learning, experiential learning, reflective practice, critical reflection, metacognitive and transformative learning. Case studies of students engaged in LTP (Mackay \& Tymon, 2013; Motion \& Burgess, 2014; Rarieya, 2005) were also examined to provide insight into the learning that occurs while in the placement. The focus of the review was to identify, in the literature, the conditions and mechanisms for student, partner, and university teacher that lead to reflective practice during LTP and the potential association between reflective practice and transformative learning.

\section{Learning Through Participation (LTP)}

A range of terms has been used to refer to courses integrating academic learning and practical experience that entail engagement with the community or the workforce. Mackaway et al. (2011) explored terms such as experience-based learning (EBL, or experiential learning), work-integrated learning (WIL), cooperative education, and service learning. Two other related terms are community service learning (Bender, 2007) and community-based research (CBR, see Stocking \& Cutforth, 2006; Strand, Marullo, Cutforth, Stoecker, \& Donohue, 2003). A few umbrella concepts have been developed to cover the range of student placements. Mackaway et al. (2011) coined the term learning through participation (LTP) to refer to all curriculum-anchored learning experiences where students engage in activities outside the classroom and that stimulate their learning by enabling them to apply knowledge and become involved with the community that exists beyond the educational institution. Curricular 
community engagement (CCE) refers to the value of linking the knowledge present in the curriculum, academic scholarship, and the community and how these can engage in mutually beneficial collaborations that simultaneously address community needs, enhance students' civic and academic learning, and develop an institution's research goals (Bender, 2007). Given that the concept of learning is key in this review, we will use the term LTP to refer to all modalities referred to above, but the authors would like to add the caveat that, in this article, the term comprises all actors involved in the process of linking academic and experiential learning through student placements, which includes students, university teachers, and relevant staff at external organisations liaising with universities.

\section{Transformative Learning-“an Emancipatory Perspective”}

Transformative learning was described by Cranton (2011, p. 76) as "an emancipatory perspective," a process that entails liberating oneself from a prior framework of understanding to admit other possible explanations. For D'Amato and Krasny (2011), transformative learning takes place when one has to reinterpret current experiences because old assumptions are no longer relevant and the cognitive system has to search for new constructs "that make the novel and confusing perceptions intelligible" (p. 239). Transformative learning, therefore, offers the learner new perspectives and encompasses "insight into the source, structure, and history of a frame of reference, as well as judging its relevance, appropriateness, and consequences" (Mezirow, 2003, p. 61). Rarieya (2005) added that transformative learning entails examining issues from both the micro and macro levels and from various dimensions, including the ethical, moral, political, and social.

In relation to student placements, Gewessler and Norris (2013) have noted that transformative learning can be generated by action-based community service. The connection between LTP experiences and transformative learning has also been explored by Trede (2012) who argued that students' workplace experiences are opportunities for meaningful learning that shapes their professional identity. In this article, we argue that, as a result of the collaborative and reflective process that emanates from working jointly on a project, this emancipatory process can be instigated by a student, a university convenor, or a placement supervisor.

\section{Transformative for All}

Lloyd, Amigó and Hettitantri (2016) found that learning generated during work experiences embedded in academic frameworks occurs not only in students but also in the other actors involved (partner organisations and university convenors). Worrall (2007) also noted the critical experiences of community partner organisations when working with students, but acknowledged the lack of research on this topic. Strand et al. (2003) noted how community-based research connects the three partners by creating a scenario that combines the elements of "abstract, generalized knowledge of the professor, detailed hands-on experiential knowledge of community members, and the fresh perspective brought by students unencumbered by community traditions and academic canons" ( $p$. 10).

It has been suggested that reflection during LTP experiences assists with meaningful learning, professional identity formation, critical thinking, and the development of new personal epistemologies (Fitch, 2011; Trede, 2012; Valle, 2006). However, the way this can be achieved has not been discussed, and the focus has been solely on the student as the one responsible and the one who benefits from that reflection. This article suggests that students' reflections on their experiential learning can have an impact on those supervising them. Both external university partners and university teachers may be exposed to new and challenging situations for the first time, which may lead to transformative learning. 


\section{Activating Transformative Learning Through Critical Reflection}

Just as Dewey's notion that reflection on experience can lead from perplexity to clarity, similarly, critical reflection on practical experience has been identified in the literature as a means of activating transformative learning (Mezirow, 2000). The process of reflecting critically requires "reassessing the way we have posed problems and reassessing our own orientation to perceiving, knowing, believing, feeling, and acting" (Mezirow, 1990, p. 13). This practice of questioning one's assumptions encourages "deeper level learning" (Mackay \& Tymon, 2013, p. 644), which may include, for example, understanding the nature of reasons and their methods, logic, and justification (Mezirow, 2003), as well as processes that examine the ethical, social, and political consequences of actions (Larrivee, 2008).

Harvey et al. (2014) argued that reflective practice can be a key component in a collaborative education curriculum because it supports learners in establishing cognitive connections between the theory discussed in a classroom and their professional experience. Bender (2007) has written that structured reflection enables students to look into their work experiences critically, and assess them in light of the expected learning outcomes for a particular unit of study. Ghaye's (2010) perspective on reflection is as an interactive undertaking that can lead to positive emotions, positive relationships, positive engagement, and purpose in the undertakings one engages in. He suggested that in order to enhance human flourishing, reflective practices should adopt a strengths-based approach-for example, focusing on making conversations of positive regard where those engaged in the process identify good and successful experiences and events and apply what they have learned to good use. Rodgers (2002) added that critical reflection serves the larger purpose of moral growth of both the individual and society. As an example, Rarieya (2005) found the students in her postgraduate teaching course had developed a visible reflective stance during the teaching practicum period and saw reflection as a tool for re-examining their practice; as one of her students stated, "reflective practice enables me to travel into myself and find out the worth of my actions" (p. 291).

Critical reflection is thus paramount to attain transformative learning because it is through reflection that a change of paradigm or a different frame of reference (Franz, 2003) can occur due to an acquired new perspective (Thorpe, 2004) or new behaviours (Rarieya, 2005; Rose \& Devonshire, 2004). In a section below, we present a model that can be used to trigger transformative learning through critical reflection for all stakeholders involved in student placements.

\section{Reflective Metacognitive Learning}

Critical reflection and its connection to transformative learning need to be understood as cognitive processes. Following from Bloom's taxonomy of staged learning processes (Bloom, Engelhart, Furst, Hill, \& Krathwohl, 1956) from actual to conceptual and procedural, Anderson and Krathwohl (2001) added a metacognitive stage, which refers to students' awareness of their own knowledge. Williams (2004) referred to metacognitive learners as those who have the knowledge and awareness to control their own learning. Three levels of metacognitive learning have been observed: strategic knowledge; knowledge about cognitive tasks; and self-knowledge, or knowledge of the self (Krathwohl, 2002; Wilson, 2016). Sheahan (2013) added that a student who exhibits evidence of metacognitive learning is more able and ready to be reflective. The authors of this article have observed how Rarieya's (2005) four levels of reflection correlate with the four revised stages of Bloom's taxonomy, and have produced a table (Table 1) that illustrates this connection. We believe there is a strong link at the fourth level between transformative reflection and metacognitive learning, especially regarding self-knowledge. 
Table 1: Levels of reflection

$\begin{array}{ll}\text { Rarieya's levels of reflection (2005) } & \text { Bloom's taxonomy: Anderson \& Krathwohl's (2001) version } \\ \text { Noticing } & \text { Factual Knowledge } \\ \text { Making meaning } & \text { Conceptual Knowledge } \\ \text { Making sense } & \text { Procedural Knowledge } \\ \text { Transformative } & \text { Metacognitive Knowledge }\end{array}$

\section{Sustainability in Education}

Rarieya's trasformative level of reflection also aligns with the premises of sustainability in education where capacity building, creativity, adaptive management, and transformative learning are integrated into liberal education practices (Sterling, 2008, p. 65). Dewey (1910/1933) wrote that meaning making grows out of, and leads back into, one's worldview -thereby demanding ongoing change through engagement in reflection. Gewessler and Norris (2013) claimed that, to respond appropriately to problems and imagine alternative futures, learners need to have the capacity to question their assumptions and beliefs. Transformative learning through reflection and dialogue is fundamental to this process. Other terminologies that have been used to refer to the new perspectives and attitudes achieved as part of these transformative learning processes are Mezirow's perspective transformation (cited in Boud, Keogh, \& Walker, 1985) and Cranton's (2011) emancipatory perspective.

\section{Current Forms of Reflective Practice}

Several tools for promoting effective reflective practice have been discussed in the literature. The reflective journal or diary is the most common one in LTP (Harvey et al., 2012), and many scholars have explored its role during student placements as an enabler for exploring thinking, feelings, emotions, and decision making (Boud, 2001; Boud et al., 1985; McAlpine, Weston, Berthiaume, Fairbank-Roch, \& Owen, 2004; Nesoff, 2004; Rarieya, 2005; Thorpe, 2004).

Other studies noted the use of blogs for reflection (Yang, 2009), and online activity rooms or hubs where students and lecturers shared an ongoing online conversation (Maor, 2003). Lloyd et al.'s study (2016) found that students in their LTP programmes used a range of technologies for collaboration and sharing experiences during their LTP programmes, including many digital platforms provided by the university (Moodle and survey tools, Skype, Dropbox, Google Drive, and online calendars), as well as personal social media platforms like Facebook. More recent developments include online applications for reflection to support students' reflective practice and learning while on placement (Harvey et al., 2016). These tools and practices, particularly those available via technology, offer the possibility to capture, through written and visual information, significant moments for later reflection. We suggest a comparative evaluation of all these tools to be undertaken to gauge the applicability, suitability, and usefulness of each.

\section{Time and Scaffolding to Reflect}

The transition between reflection and transformation is not immediate and requires time (Fitch, 2011; Mezirow, 1990). According to Mezirow (1990), transformative learning only occurs after completion of experience, so there needs to be a hiatus between action and transformation where reflection and a reassessment, or transformation, of perspectives can occur. Coulson and Harvey (2013) also acknowledged that time is required to acquire the skills necessary to be competent, so they recommended reflection takes place before, throughout, and after the placement thereby enabling 
the students to enhance the complexity of their reflection. But they argued that only a few students are innately reflective so all students should be taught critical reflective skills early on, before they commence their LTP activities (Coulson \& Harvey, 2013).

Rose and Devonshire used the term scaffolding (2004, p. 309) to prepare students to engage independently in reflection, endorsing Vygotsky's assertion that learners require interaction with and support from teachers to develop their reflective skills (Sawyer, 2006). Other authors (Coulson \& Harvey, 2013; Harford \& MacRuairc, 2008; Whipp, 2003) also emphasised the need for scaffolded reflection with a progressive reduction of teacher-led reflection.

A model for scaffolding reflection using journals during placements was suggested by Boud (2001), who recommended three stages: reflecting on questions prior commencement of the placement, in the midst of the action, and at the end. McAlpine et al. (2004) added a fourth stage-at some point after the placement has concluded-suggesting "it is conceivable that a more contemplative opportunity for reflection-on-action well after the course may lead to more questioning and construction of knowledge" (p. 365). Our SPROUT model, described below, proposes that scaffolding should apply to all parties in the triad-undertaking reflection as part of their transformative learning process. SPROUT also encompasses the fourth stage in the reflective process-reflection after a significant period of time-to enable the time lapse to contribute to the potential transformation.

\section{Dialogue Across the Triad}

For Dewey (1933), reflection is an intrinsic part of learning; we think in order to learn. Although his focus was on teachers and students, we posit reflection for learning is equally relevant for community partners engaged in LTP activities. In her study of reflective practice by postgraduate education students, Rarieya (2005) found that the students who reached the transformative level continually engaged in a dialogue with their tutors and, as a result, immersed themselves in the reflection process. Dialogue between students was also promoted by Boud (2001) who explored how students who were exposed to the notion of "learning is reason for being" and worked in pairs or teams, began transforming their perspectives, and challenging their old patterns of learning (pp. 14-15). Gewessler and Norris (2013) argued that dialogue is a crucial element of a sustainable curriculum. Another form of dialogue is what Hays and Swanson (2012) referred to as reverse mentoring to convey the bidirectional nature of learning and teaching within organisations. They discussed the importance of recognising that knowledge exists at all levels of the workplace, and argued that those who engage in dialogue with both more and less experienced coworkers are in an advantageous position.

\section{The Reflective Triad}

The literature discussed above supports the view that a meaningful and transformative learning outcome for students may arise following an engaged, conscientious, thorough, and critically reflective process that challenges previous assumptions and frames of reference. In this section, we argue that the reflective process during LTP should also extend to the university teacher and the partner organisation supervisor, and we then present the SPROUT model to suggest how this can be achieved.

There has been much emphasis on the value of reflection for educators (see, for example, Brandt, 2008; Kreber, 2006; Larrivee, 2008; and Yang, 2009 for specific references to university teachers). Larrivee (2008, p. 346) stated: "[Teachers] must be reflective practitioners themselves, capable of remaining open to viewpoints different from their own, letting go of the need to be right, and acknowledging their own limiting assumptions." In the context of university teaching, Coulson and Harvey (2013) acknowledged that not all teachers are competent in both the practice and teaching of reflection, so they proposed that teachers practise critical reflection themselves. Maor (2003) 
identified that teachers who wish to inspire their students to become reflective practitioners need to simultaneously maintain their own reflective practice. Mackay and Tymon (2013) wrote that when reflective practice is taught to university students, it is crucial that educators reflect upon their own teaching practice so they can discuss its challenges with students.

In terms of reflection as it refers to the host organisation's supervisors, Bringle and Hatcher (2002) found that through offering student placements, community partners may experience a transformation in their own perception of the experience. They stated that with some close partnerships there could be a shift from "an exclusively exchange orientation to a more communal one" where joint outcomes and a longer-term outlook are considered (p. 511). However, the research on the role of external partners' critical reflection and learning as a result of LTP activities is very limited. It is the purpose of this paper and of our SPROUT model below to encourage a more nuanced collaboration amongst the triad, as well as a commitment to mutual learning that may lead to transformative action.

\section{SPROUT: Our Model to Produce Transformative Learning}

Although much has been written on reflective practice and its role in transformative learning, and the authors have anecdotal evidence that it happens, we are still not cognisant of the actual individual and collaborative processes and pedagogical mechanisms that make this possible. With this in mind, and based on the writings of Rarieya (2005), Thorpe (2004), Boud (2001), and McAlpine et al. (2004), we propose a model that could assist all LTP stakeholders to achieve transformative learning. We believe that this model prompts LTP participants to consider new perspectives and values that may lead to continuous and sustainable learning (Sterling, 2008, p. 65). It has not yet been trialled and evaluated to ascertain its effectiveness.

SPROUT is an acronym for sustainability, participation, reflection, outward focus (dialogue and communication), understanding (making sense), and transformation. The acronym covers all the aspirations we consider to be intrinsic to our structured, scaffolded approach to transformative learning, specifically as it relates to LTP. We have designed a model (see Table 2: SPROUT seminar programme) that uses reflective practice over time so that a transformative and sustainable learning process can occur with the development of metacognitive, higher order, and critical thinking skills. We believe this transformation can equally apply to students, participating university convenors, and partner organisations - the triad. SPROUT encompasses preparation, appropriate tools, collaboration and review, dialogue, and mutual support by all participants as well as reflection after action. SPROUT offers the structure and tools for four sequential steps-or moments-to develop higher-order reflection and metacognitive learning skills. It is based on the stages of learning and preparation for journal writing, as proposed by Boud (2001) and McAlpine et al. (2004): pre commencement, during, at the conclusion, and afterwards. SPROUT is designed around three seminars or workshops that the students would attend at their universities while completing a period of LTP and a follow-up survey. The suggested structure and content is explored below.

We acknowledge that encouraging and supporting placement partners to actively reflect may require a more nuanced approach because there can be no expectations placed on them; engaging in reflection has to be their choice. They would be encouraged to attend the seminars, but an additional printable or online version of the workshops would be provided for their benefit. They would also be able to participate in shared online spaces and forums to enable them to assess changes in themselves and others in the triad, as well as to provide feedback. There is also an imperative for the convenor to participate in reflection to enhance her or his teaching, learning, and action research, as noted by Rodgers (2002) and Leitch and Day (2000). 
Students may not be psychologically and emotionally ready to employ a critical perspective when they engage in LTP (Coulson \& Harvey, 2013); therefore, the model proposes an introductory session to critical reflection. It also recommends the use of a range of reflection tools and encourages participants to build up evidence of the journey towards transformative learning. It is designed to be broad-based enough to accommodate different disciplines and individual differences, as identified by Mackaway et al. (2011). It aims to make participants feel comfortable disclosing their thoughts, especially those whose cultural backgrounds may inhibit them from discussing or reflecting on personal experiences. The model also encourages dialogue across the triad (as recommended by Boud, 2001; Gewessler \& Norris, 2013; Hays \& Swanson, 2012; Rarieya, 2005). The reverse mentoring technique (Hays \& Swanson, 2012) is also incorporated. A trained moderator should of course run the seminars, and the authors acknowledge that given potential limitations in ensuring all three groups are physically present at the same time, sessions via Skype, webinars, or even blogs, could replace face-to-face encounters. Below, we have outlined how the model can be implemented.

Table 2: The SPROUT seminar programme

\begin{tabular}{|c|c|}
\hline Seminar One & Prior to placement-preparing for reflection \\
\hline $\begin{array}{l}\text { Prior to commencement of placements, a } \\
\text { seminar is run to support learners. } \\
\text { Students, partners, and university } \\
\text { teachers are all invited to attend. }\end{array}$ & $\begin{array}{l}\text { The aim of this workshop is to encourage students, } \\
\text { teachers, and partners to consider critical reflection by: } \\
\text { - discussing the value of reflection and dialogue } \\
\text { - introducing the theory and practice of critical reflection } \\
\text { (also made available as a printed/online resource) } \\
\text { - discussing the tools available to suit individual needs } \\
\text { (journals, blogs, photographic records, online } \\
\text { applications, online forums etc.) } \\
\text { - providing spaces and platforms for interaction with } \\
\text { other learners, and establishing groups where relevant } \\
\text { - establishing an achievable time frame, with specified } \\
\text { points during the project when reflection should take } \\
\text { place. }\end{array}$ \\
\hline
\end{tabular}

During placement-ongoing reflective practice

Following Seminar One and prior to commencement, participants should establish reflective practices to respond to the new experiences, roles, and contexts. They will be encouraged to implement the practice from the beginning of the placement until after completion.
Participants will be encouraged to do this by:

- learning about the theories of metacognitive learning and education for sustainability

- laying out their assumptions about the placement and what to expect

- addressing emerging issues and answering the "why" questions that connect them with their own presumptions and frames of reference (e.g., Thorpe, 2004)

- ensuring ongoing dialogue is established and encouraged within their triad, as well as with other students (at their placement or in the class) through one or more of the following mediums, as suitable: online forums, social media, email, phone, in person during the placement, and through any other means

- discussing the development of each of the stakeholder's personal reflection

- observing how critical reflection practice is being integrated into their experiences

- giving presentations on any ethical dilemmas and observations of their organisation's role in society. 
The final seminar enables the triad to analyse what they learned through the process and whether it has challenged their worldviews in any way.
This will be achieved by:

- Teachers and partners providing feedback on any assessment task requiring the application of critical reflection by the students and the value of the appropriate reflection platforms used (e.g., web-based, face-to-face). By providing feedback, teachers and partners will then be able to assess how students' reflective tasks prompt them to critically consider their own learning.

- Discussing whether participants have identified any changes and how they plan to implement their learnings in future practices. Members of the triad will be encouraged to consider positive changes within their own domains.

- Assessing the sustainability of those changes and the challenges to making those changes sustainable.

\begin{tabular}{|c|c|}
\hline Survey & Post-completion \\
\hline $\begin{array}{l}\text { Once students have completed a subject it } \\
\text { is difficult for their convenor to maintain } \\
\text { contact with them. Consequently, it would } \\
\text { be productive to commit students, } \\
\text { convenors, and partners to complete a } \\
\text { survey six months post completion of a } \\
\text { placement. This would be a way to } \\
\text { evaluate whether transformation has } \\
\text { taken place and whether it has been } \\
\text { sustained. The survey would look for } \\
\text { evidence of the incorporation of a new } \\
\text { worldview into specific practices beyond } \\
\text { the LTP experience. }\end{array}$ & $\begin{array}{l}\text { The survey would cover if and how: } \\
\text { - students apply and embed new behaviours, knowledge, } \\
\text { skills, and attitudes in other subjects and beyond } \\
\text { university, in the workplace, their lives, and } \\
\text { relationships } \\
\text { - } \text { students, convenors and partners maintain reflective } \\
\text { practices after the completion of the placement } \\
\text { - participants sustain the impact of critical reflection on } \\
\text { their lives (for students, this would be evidenced in new } \\
\text { behaviours like joining new clubs and societies, taking } \\
\text { on student leadership roles, or volunteering in the } \\
\text { community and seeking employment in civil society } \\
\text { organisations) } \\
\text { participants have maintained contact with the } \\
\text { placement/student/university (in voluntary, paid, or } \\
\text { social roles, including mentoring roles). }\end{array}$ \\
\hline
\end{tabular}

In addition to an online survey, the need for contact between the convenor and students may become evident at the fourth stage - that is, some time after the conclusion of the placement and the coursebecause this is when the transformation occurs, as various authors have pointed out (Boud, 2001; McAlpine et al., 2004; Mezirow, 1990; Rarieya, 2005; Thorpe, 2004).

\section{Conclusion and Recommendations}

The authors have found that participation in LTP projects may enable students to undergo transformative learning through the application of critical reflection. Further, this article suggests university partners and convenors may also experience transformative learning when they get involved in critical reflection through a student's project. This needs to be explored in greater depth because there is currently no research available on this topic. We believe SPROUT is one way of investigating this proposition but it requires implementation, evaluation, and review.

This article has also identified the various tools that enable students to reflect, both individually and in dialogue with others, on their LTP experiences. The authors found that, in order for critical reflection 
to be transformative, reflection needs to be structured and convenors are required to have skills and experience in reflective practice themselves so they can support their students (Coulson \& Harvey, 2013).

We have discussed how transformative learning may encourage change at various levels through LTP. Our analysis has also raised the potential for other LTP areas to be investigated further, including:

- how best to train convenors, partners, and students in critical reflection

- the range of reflective tools available and their usability

- how reflective practice can be incorporated into the curriculum of all LTP subjects

- how in LTP reflection can be designed for not only students but also for partners and teachers to critically engage through the LTP activity

- how reflective practice in higher education can be assessed

- the value of reflective practice in higher education (at subject, faculty, and university levels)

- the impact of the student's transformative journey on the partner and university convenor and whether, with appropriate scaffolding, they may also experience transformative learning and if this process could be the precursor for meaningful and collaborative social change.

This is an area ripe for further research. Simple models like SPROUT may provide the opportunity for learning institutions to build capacity with new and existing partners and, at the same time, provide an exemplary learning opportunity for students. Developing a model that brings together students, university convenors, and partners is important for all parties, because, as stated by Sandy and Holland (2006, p. 30), "What we're learning to do, whether we're students or whether we're a non-profit, is doing something that is actually moving us as a community."

\section{References}

Australian Collaborative Education Network (ACEN). (2015). National strategy on work integrated learning in university education. Retrieved from http://cdn1.acen.edu.au/wpcontent/uploads/2015/03/National-WIL-Strategy-in-university-education-032015.pdf

Anderson, L. W., \& Krathwohl, D. (Eds.) (2001). A taxonomy for learning, teaching and assessing: A revision of Bloom's taxonomy of educational objectives. New York, USA: Longman.

Archer, M. S. (2012). The reflexive imperative in late modernity. New York, USA: Cambridge University Press.

Bender, C. G. (2007). Pathways of change for integrating community service-learning into the core curriculum. Education as Change, 11(3), 127-142.

Bloom, B. S., Engelhart, M. D., Furst, E. J., Hill, W. H., \& Krathwohl, D. R. (1956). Taxonomy of educational objectives, Handbook I: The cognitive domain . New York, USA: David McKay.

Boud, D. (2001). Using journal writing to enhance reflective practice. New Directions for Adult and Continuing Education, 2001(90), 9-18.

Boud, D., Keogh, R., \& Walker, D. (1985). Promoting reflection in learning: A model. In D. Boud, R. Keogh, \& D. Walker (Eds.), Reflection: Turning experience into learning (pp. 18-40). Abingdon, UK: Routledge. 
Brandt, C. (2008). Integrating feedback and reflection in teacher preparation. ELT Journal, 62(1), 3746.

Bringle, R., \& Hatcher, A. (2002). Campus-community partnerships: The terms of engagement. Journal of Social Issues, 58(3), 503-516.

Coulson, D., \& Harvey, M. (2013). Scaffolding student reflection for experience-based learning: A framework. Teaching in Higher Education, 18(4), 401-413.

Cranton, P. (2011). A transformative perspective on the scholarship of teaching and learning. Higher Education Research and Development, 30(1), 75-86.

D'Amato, L. G., \& Krasny, M. E. (2011). Outdoor adventure education: Applying transformative learning theory to understanding instrumental learning and personal growth in environmental education. The Journal of Environmental Education, 42(4), 237-254.

Dewey, J. (1933). How we think. Buffalo, New York: Prometheus. (Original work published 1910)

Fitch, K. (2011). Developing professionals: Student experiences of a real-client project. Higher Education Research and Development, 30(4), 491-503.

Franz, N. K. (2003). Transformative learning in extension staff partnerships: Facilitating personal, joint, and organizational change. Journal of Extension, 41(2). Retrieved from https://www.joe.org/joe/2003april/a1.php

Gewessler, A., \& Norris, K. (2013). Embedding sustainability into teaching, learning and curriculum in the learning and skills sector. Learning and Skills Improvement Service. Retrieved from http://webarchive.nationalarchives.gov.uk/20130802100617/http:/lsis.org.uk/publicationcontent/embedding-sustainability-teaching-learning-and-curriculum-learning-and-skills

Ghaye, T. (2010). In what ways can reflective practices enhance human flourishing? Reflective Practice, 11(1), 1-7. doi:10.1080/14623940903525132

Harford, J., \& MacRuairc, G. (2008). Engaging student teachers in meaningful reflective practice. Teaching and Teacher Education, 24(7), 1884-1892.

Harvey, M., Baker, M., Bosanquet, A., Coulson, D., Semple, A. L., \& Warren, V. (2012, November). Moving beyond the diary: Innovation in design and delivery of reflection. Paper presented at the Australian Collaborative Education Network National Conference, Geelong, Australia.

Harvey, M., Baker, M., Fredericks, V., Lloyd, K., McLachlan, K., Semple, A., \& Walkerden, G. (2014, October). Reflection: Alignment of practice as a strategy for building capacity for learning. Paper presented at the Australian Collaborative Education Network, Tweed Heads, Australia.

Harvey, M., Walkerden, G., Semple, A. L., McLachlan, K., Lloyd, K., \& Baker, M. (2016). A song and a dance: Being inclusive and creative in practicing and documenting reflection for learning. Journal of University Teaching and Learning Practice, 13(2). Retrieved from http://ro.uow.edu.au/jutlp/vol13/iss2/3/?utm source=ro.uow.edu.au\%2Fjutlp\%2Fvol13\%2Fiss2 \%2F3\&utm medium=PDF\&utm campaign=PDFCoverPages

Hays, B. A., \& Swanson, D. J. (2012). Public relations practitioners' use of reverse mentoring in the development of powerful professional relationships. PRism, 9(2). Retrieved from http://www.prismjournal.org/fileadmin/9 2/Hays Swanson.pdf

Krathwohl, D. R. (2002). A revision of Bloom's taxonomy: An overview. Theory Into Practice, 41(4), 212218.

Kreber, C. (2006). Developing the scholarship of teaching through transformative learning. Journal of the Scholarship of Teaching and Learning, 6(1), 88-109. 
Larrivee, B. (2008). Development of a tool to assess teachers' level of reflective practice. Reflective Practice, 9(3), 341-360.

Leitch, R., \& Day, C. (2000). Action research and reflective practice: Towards a holistic view. Educational Action Research, 8(1), 179-193.

Lloyd, J., Amigó, M., \& Hettitantri, N. (2016). Learning through participation as a mass collaboration. Asia-Pacific Journal of Cooperative Education, 17(2), 163-174.

Mackaway, J. A., Winchester-Seeto, T., Coulson, D., \& Harvey, M. (2011). Practical and pedagogical aspects of learning through participation: The LTP assessment design framework. Journal of University Teaching and Learning Practice, 8(3), Art. 5. Retrieved from http://ro.uow.edu.au/cgi/viewcontent.cgi?article=1183\&context=jutlp

Mackay, M., \& Tymon, A. (2013). Working with uncertainty to support the teaching of critical reflection. Teaching in Higher Education, 18(6), 643-655.

Maor, D. (2003). The teacher's role in developing interaction and reflection in an online learning community. Educational Media International, 40(1-2), 127-138.

McAlpine, L., Weston, C., Berthiaume, D., Fairbank-Roch, G., \& Owen, M. (2004). Reflection on teaching: Types and goals of reflection. Educational Research and Evaluation, 10(4-6), 337-363.

Mezirow, J. (1990). How critical reflection triggers transformative learning. In J. Mezirow \& Associates (Eds.), Fostering critical reflection in adulthood: A guide to transformative and emancipatory learning (pp. 1-20). San Francisco, USA. Jossey-Bass.

Mezirow, J. (2000). Learning as transformation: Critical perspectives on a theory in progress. San Francisco, USA. Jossey-Bass.

Mezirow, J. (2003). Transformative learning as discourse. Journal of Transformative Education, 1(1), 58-63.

Motion, J., \& Burgess, L. (2014). Transformative learning approaches for public relations pedagogy. Higher Education Research and Development, 33(3), 523-533.

Nesoff, I. (2004). Student journals: A tool for encouraging self-reflection and critical thought. Journal of Baccalaureate Social Work, 10(1), 46-60.

Rarieya, J. F. A. (2005). Promoting and investigating students' uptake of reflective practice: A Pakistan case. Reflective Practice, 6(2), 285-294.

Rodgers, C. (2002). Defining reflection: Another look at John Dewey and reflective thinking. Teachers College Record, 104(4), 842-866.

Rose, M., \& Devonshire, E. (2004). Rethinking reflection: Using online reflective learning in professional practice for Indigenous health workers. Education Media International, 41(4), 307-14.

Sandy, M., \& Holland, B. A. (2006). Different worlds and common ground: Community partner perspectives on campus-community partnerships. Michigan Journal of Community Service Learning, 13(1), 30-43.

Sawyer, R. K. (2006). The Cambridge handbook of the learning sciences. New York, USA: Cambridge University Press.

Sheahan, E. (2013). Fostering transformative learning for Grade 3 students preparing for EQAO examinations (Unpublished master's thesis). Queen's University, Canada. Retrieved from https://qspace.library.queensu.ca/handle/1974/8151.

Sterling, S. (2008). Sustainable education: Towards a deep learning response to unsustainability. Policy and Practice: A Development Education Review, (6), 63-68. 
Stocking, V. B., \& Cutforth, N. (2006). Managing the challenges of teaching community-based research courses: Insights from two instructors. Michigan Journal of Community Service Learning, 13(1), $56-$ 65.

Strand, K., Marullo, S., Cutforth, N., Stoecker, R., \& Donohue, P. (2003). Principles of best practice for community-based research. Michigan Journal of Community Service Learning, 9(3), 5-15.

Thorpe, K. (2004). Reflective learning journals: From concept to practice. Reflective Practice, 5(3), 327343.

Trede, F. (2012). Role of work-integrated learning in developing professionalism and professional identity. Asia-Pacific Journal of Cooperative Education, 13(3), 159-167.

Valle, M. (2006). A model of engaged learning for the 21st century. Journal of Academic Administration in Higher Education, 1(1-2), 49-56.

Whipp, J. L. (2003). Scaffolding critical reflection in online discussions: Helping prospective teachers think deeply about field experiences in urban schools. Journal of Teacher Education, 54(4), 321333.

Williams, J. (2004). Metacognition in primary schools: What does it look like? PEEL Seeds, 70, 1-2.

Wilson, L. (2016). The second principle: A succinct discussion of the revisions to Bloom's classic cognitive taxonomy by Anderson and Krathwohl and how to use them effectively. Retrieved from http://thesecondprinciple.com/teaching-essentials/beyond-bloom-cognitive-taxonomy-revised/

Worrall, L. (2007). Asking the community: A case study of community partner perspectives. Michigan Journal of Community Service Learning, 14(1), 5-17.

Yang, S. H. (2009). Using blogs to enhance critical reflection and community of practice. Journal of Educational Technology and Society, 12(2), 11-21. 